\title{
Effects of Bacillus subtilis var. natto products on symptoms caused by blood flow disturbance in female patients with lifestyle diseases
}

This article was published in the following Dove Press journal:

International Journal of General Medicine

20 January 2015

Number of times this article has been viewed

\section{Masahito Hitosugi ${ }^{1,2}$ \\ Katsuo Hamada ${ }^{2}$ \\ Kazutaka Misaka ${ }^{2}$}

'Department of Legal Medicine, Shiga University of Medical Science, Otsu, Shiga, Japan; ${ }^{2}$ Department of Internal Medicine, Nagareyama Central Hospital, Nagareyama, Chiba, Japan
Correspondence: Masahito Hitosugi, Department of Legal Medicine, Shiga University of Medical Science, Tsukinowa, Seta, Otsu,

Shiga 520-2192, Japan

Tel +8I 775482200

Fax +8I 775482200

Email hitosugi@belle.shiga-med.ac.jp

\begin{abstract}
The fermented soybean product natto is a popular traditional food in Japan and is considered a health supplement. $\mathrm{NKCP}^{\circledR}$, a natto-derived dietary food supplement whose main component is bacillopeptidase F, has antithrombotic, fibrinolytic, and blood pressure-lowering effects. We examined whether daily intake of $\mathrm{NKCP}^{\circledR}$ effectively improves subjective symptoms in patients with lifestyle diseases in this cross-over, double-blind study. Fermented soya extract with subtilisin NAT (nattokinase) as the main component was used as an active placebo. A 4-week course of $\mathrm{NKCP}^{\circledR}$ significantly decreased the visual analog scale (VAS) score for shoulder stiffness from 42.3 to 32.4 ( $P=0.009$ ), the VAS score for low back pain from 25.5 to $18.8(P=0.02)$, and the VAS score for coldness of the extremities from 33.1 to $25.7(P=0.002)$. However, no significant difference was found in the VAS score for headache. After a 4-week course of active placebo, no significant changes in the VAS score were found for any symptoms. The significant improvement in the symptoms secondary to blood flow disturbance was caused by the improvement in blood flow by $\mathrm{NKCP}^{\circledR}$. The use of dietary supplements based on the Japanese traditional food natto helps to relieve subjective symptoms for patients with lifestyle diseases receiving medical care.
\end{abstract}

Keywords: bacillopeptidase F, Japanese traditional food, lifestyle disease, subjective symptom, supplement

\section{Introduction}

Recently, traditional Japanese foods have attracted attention because of Japan's lower prevalence of cardiovascular diseases and the Japanese population's longer life expectancy that exceed life expectancy in Western countries. ${ }^{1,2}$ In 2013, the food culture of Japan was added to the United Nations Educational, Scientific, and Cultural Organization (UNESCO) List of Intangible Cultural Heritage. ${ }^{3}$ Natto, the fermented soybean product, is a popular traditional food in Japan. When forming natto, the soya beans are first soaked and cooked, then friendly starter bacteria are added, and the soya beans are allowed to develop under warm and damp conditions. Natto is considered a health supplement because of its high amount of nutrients: $100 \mathrm{~g}$ of natto contains a variety of amino acids (16 g), vitamin $B_{1}(0.07 \mathrm{mg})$, vitamin $\mathrm{B}_{2}(0.56 \mathrm{mg})$, vitamin $\mathrm{B}_{6}(0.24 \mathrm{mg})$, fibers $(6.7 \mathrm{~g})$, and so on. Bacillus subtilis var. natto, a bacterium isolate from natto, secretes several proteases during soybean fermentation. Of them, bacillopeptidase F and subtilisin NAT (nattokinase) are considered to have fibrinolytic activity. ${ }^{4-6}$ Both substances are supplied as dietary supplements because of their positive effects on blood flow; the former is present in $\mathrm{NKCP}^{\circledR}$, and the latter is present in fermented soya extract. ${ }^{4-6}$ The anticoagulant, fibrinolytic, and blood pressure-lowering effects of both substances have 
been compared, and $\mathrm{NKCP}^{\circledR}$ has been scientifically confirmed to have dominant effects. ${ }^{7,8} \mathrm{NKCP}^{\circledR}$ has a 2.5 -fold greater fibrinolytic effect and a $>100$-fold anticoagulant effect in human blood; it also causes a significantly greater reduction in blood pressure in patients with lifestyle diseases including essential hypertension, type 2 diabetes, or hyperlipidemia than does fermented soya extract. ${ }^{7,8}$

Because endothelial and platelet dysfunction as well as coagulation and fibrinolysis abnormalities more often occur in patients with than without hypertension, diabetes mellitus, or hyperlipidemia, we speculated that changes in blood fluidity improve symptoms caused by blood flow disturbances in such patients. ${ }^{9}$ In this study, therefore, we examined whether daily intake of the nutritional supplement $\mathrm{NKCP}^{\circledR}$ helps to improve subjective symptoms in patients with lifestyle diseases.

\section{Methods}

\section{Study design}

Patients who regularly visit the hospital or clinics with essential hypertension, type 2 diabetes, or hyperlipidemia were considered eligible for this study. This study was performed at three facilities in Japan (Nagareyama Central Hospital, Nagareyama; Ichihashi Clinic, Kobe; and Hanzoumon Clinic, Tokyo). Essential hypertension is defined as systolic blood pressure of $140 \mathrm{mmHg}$ or more and/or diastolic blood pressure of $90 \mathrm{mmHg}$ or more. Hyperlipidemia was defined as low-density lipoprotein cholesterol greater than $140 \mathrm{mg} / \mathrm{dL}$, triglycerides greater than $150 \mathrm{mg} / \mathrm{dL}$, or high-density lipoprotein cholesterol less than $40 \mathrm{mg} / \mathrm{mL}$. Type 2 diabetes was defined as fasting plasma glucose greater than $126 \mathrm{mg} / \mathrm{dL}$, random plasma glucose greater than or equal to $200 \mathrm{mg} / \mathrm{dL}$, or 2-hour glucose in the oral glucose tolerance test greater than or equal to $200 \mathrm{mg} / \mathrm{dL}$. We excluded patients who were pregnant or possibly pregnant, were enrolled in another clinical trial, or patients with unstable angina, acute myocardial infarction, chronic obstructive pulmonary disease, renal insufficiency, acute liver disease, infectious disease, allergies to drugs or food, or any other serious life-threatening illness. Finally, 17 female patients with a mean age of 67.8 years (range, 55-85 years) participated in this study. The characteristics of all participants are shown in Table 1. All patients were nonsmokers and took concomitant medications, including lipid-lowering agents, antidiabetic drugs, or/ and antihypertensive drugs. No changes were made to the pharmacological regimens of the patients during the course of the study.

\section{Substance description}

The substance used in the present study was $\mathrm{NKCP}^{\circledR}$ (250 mg/day, twice daily), the main component of which is bacillopeptidase F (Daiwa Pharmaceutical Co, Ltd, Tokyo, Japan). Fermented soya extract (100 mg/day, twice daily), the main component of which was subtilisin NAT, was used as the active placebo (Japan Bio Science Laboratory Co, Ltd, Osaka, Japan). Each dose was the quantity recommended

Table I Characteristics of participants

\begin{tabular}{|c|c|c|c|c|c|c|}
\hline \multirow[t]{2}{*}{ No } & \multirow[t]{2}{*}{ Age } & \multirow{2}{*}{$\begin{array}{l}\text { Body } \\
\text { height }(\mathrm{cm})\end{array}$} & \multirow{2}{*}{$\begin{array}{l}\text { Body } \\
\text { weight (kg) }\end{array}$} & \multicolumn{3}{|l|}{ Symptom } \\
\hline & & & & Hypertension & Type 2 diabetes & Hyperlipidemia \\
\hline I & 76 & 150 & 47 & & & 0 \\
\hline 2 & 69 & 150 & 48 & O & & \\
\hline 3 & 85 & $|5|$ & 45 & O & & O \\
\hline 4 & 68 & 155 & 57 & $\mathrm{O}$ & & O \\
\hline 5 & 68 & 159 & 48 & $\mathrm{O}$ & & \\
\hline 6 & 61 & 160 & 71 & O & & 0 \\
\hline 7 & 71 & 153 & 52 & O & & 0 \\
\hline 8 & 63 & 148 & 56 & O & & 0 \\
\hline 9 & 59 & 150 & 66 & $\mathrm{O}$ & & \\
\hline 10 & 77 & 138 & 63 & O & O & O \\
\hline II & 74 & 157 & 45 & O & 0 & 0 \\
\hline 12 & 71 & 149 & 48 & O & & O \\
\hline 13 & 55 & 163 & 76 & O & O & \\
\hline 14 & 62 & 152 & 62 & O & & \\
\hline 15 & 71 & 162 & 53 & O & O & \\
\hline 16 & 55 & 154 & 49 & & & 0 \\
\hline 17 & 68 & 162 & 76 & 0 & 0 & \\
\hline
\end{tabular}

Abbreviations: No, identifying number of patient; $O$, suffering from this symptom. 
by each manufacturer. The patients could not discriminate between the two substances. The cross-over, double-blind study was performed. The patient received one substance for 4 weeks, was observed for 4 weeks without receiving a substance, and then received another substance for 4 weeks. There were no adverse substance-related effects. Written informed consent was obtained from all patients before participating in the study. This study design was approved by the Shiba Palace Clinic Ethics Committee (Tokyo, Japan).

\section{Parameters}

Body height and weight were measured in the morning, and blood samples for laboratory assays were obtained before and after the administration of each substance. Samples were obtained following an overnight fast. Blood tests consisted of blood count (white blood cells, red blood cells, hematocrit, and hemoglobin); blood chemistry (total protein, albumin, blood urea nitrogen, creatinine, total bilirubin, aspartate aminotransferase, alanine aminotransferase, $\gamma$-glutamyl transpeptidase, lactate dehydrogenase, alkaline phosphatase, cholinesterase, creatine kinase, total cholesterol, low-density lipoprotein cholesterol, high-density lipoprotein cholesterol, triglycerides, blood sugar, and glycated hemoglobin $\left[\mathrm{HbA}_{1 c}\right]$ ); and D-dimer assay. Before and after administration of each substance, the patients reported their state of headache, shoulder stiffness, low back pain, and coldness of the extremities. A visual analog scale (VAS), anchored with "no symptom" on the left and "extreme symptom" on the right, was used to rate the intensity of the symptoms. The patients were asked to schematically plot their perceived symptom level at rest.

\section{Statistical analysis}

The Wilcoxon signed rank test was used to compare the laboratory and physical data or VAS scores before and after using each substance. Differences with a $P$-value of $<0.05$ were considered to be statistically significant.

\section{Results Physical findings}

The mean height of all participants was $153.7 \pm 1.5 \mathrm{~cm}$ (mean \pm standard error), mean weight was $56.5 \pm 2.6 \mathrm{~kg}$, mean body mass index was $23.9 \pm 1.1$. When using each substance, mean body weight of the participants did not change significantly $\left(\mathrm{NKCP}^{\circledR}\right.$ range, $56.6-56.8 \mathrm{~kg}, P=0.44$; active placebo range, $56.5-56.4 \mathrm{~kg}, P=0.81)$. Regarding the blood pressure of the participants, a 4-week course of $\mathrm{NKCP}^{\circledR}$ significantly decreased the mean value of systolic blood pressure from 130.3 to $111.8 \mathrm{mmHg}(P=0.002)$ and that of diastolic blood pressure from 72.9 to $69.1 \mathrm{mmHg}$ ( $P=0.024$ ). However, after a 4 -week course of active placebo, no significant changes in either systolic or diastolic blood pressure were found (124.1 vs $123.1 \mathrm{mmHg}$, and 70.1 vs $68.6 \mathrm{mmHg}$, respectively).

\section{Blood tests}

The average baseline complete blood count, protein level, liver function parameters, renal function parameters, and electrolyte level were normal before the administration of each substance (Table 2). The D-dimer levels and blood glucose levels before using $\mathrm{NKCP}^{\circledR}$ and active placebo, and the triglyceride levels before using active placebo, were higher than their respective reference ranges. Other values were within the reference ranges. No significant differences were found when the baseline values of all laboratory findings were compared between the $\mathrm{NKCP}^{\circledR}$ and active placebo group.

Regarding the comparison before and after using the substances, no significant differences were found in the laboratory parameters before and after the 4-week administration of $\mathrm{NKCP}^{\circledR}$, with the exception of cholinesterase and $\mathrm{HbA}_{1 c}$ ( $P=0.03$ and 0.04 , respectively). However, the values of these two parameters were within the reference ranges. Likewise, no significant differences in these parameters were found in patients taking active placebo, with the exception of the platelet count and cholinesterase level, which were within the reference ranges ( $P=0.01$ and 0.02 , respectively; Table 1$)$.

\section{Subjective symptoms}

First, no significant differences were found in the baseline VAS scores for headache, shoulder stiffness, low back pain, or coldness of the extremities between $\mathrm{NKCP}^{\circledR}$ and active placebo group. Next, changes in the VAS scores were compared after the administration of $\mathrm{NKCP}^{\circledR}$ and active placebo (Figures 1-4). A 4-week course of $\mathrm{NKCP}^{\circledR}$ significantly decreased the VAS score of shoulder stiffness from 42.3 to 32.4 ( $P=0.009$ ), that of low back pain from 25.5 to 18.8 $(P=0.02)$, and that of coldness of the extremities from 33.1 to 25.7 ( $P=0.002$ ). However, no significant difference was found in the VAS score for headache $(P=0.17)$. For the active placebo group, no significant changes in the VAS score for each symptom were found after the 4-week course.

\section{Discussion}

With the increase of the aging in developed countries, chronic diseases, such as diabetes, hypertension, cardiovascular disease, and osteoporosis are also on the rise. Most of patients of these diseases suffer from any symptoms in accordance 
Table 2 Changes in blood test parameters between baseline and after 4 weeks of administration of NKCP ${ }^{\circledR}$ and active placebo

\begin{tabular}{|c|c|c|c|c|c|c|}
\hline \multirow[t]{2}{*}{ Parameter } & \multicolumn{3}{|l|}{ NKCP* } & \multicolumn{3}{|c|}{ Active placebo } \\
\hline & Baseline & 4 weeks & $P$-value & Baseline & 4 weeks & $P$-value \\
\hline Red blood cell count $(\times 10,000 \mu \mathrm{L})$ & $440.9 \pm 11.2$ & $437.4 \pm 11.3$ & 0.168 & $435.1 \pm 11.9$ & $442.1 \pm 11.6$ & 0.155 \\
\hline White blood cell count $(/ \mu \mathrm{L})$ & $5,7 \mid 7.1 \pm 28.22$ & $5,963.5 \pm 217.6$ & 0.436 & $5,685.9 \pm 253.7$ & $5,768.2 \pm 284.5$ & 0.667 \\
\hline Hemoglobin content $(g / d L)$ & $13.4 \pm 0.30$ & $|3.3 \pm 0.3|$ & 0.211 & $|3.3 \pm 0.3|$ & $|3.5 \pm 0.3|$ & 0.138 \\
\hline Hematocrit (\%) & $40.6 \pm 0.83$ & $40.2 \pm 0.81$ & 0.104 & $40.1 \pm 0.85$ & $41.0 \pm 0.83$ & $0.049 *$ \\
\hline Blood platelet count $(\times 10,000 \mu \mathrm{L})$ & $21.2 \pm 0.74$ & $21.8 \pm 0.64$ & 0.667 & $21.9 \pm 0.67$ & $22.8 \pm 0.75$ & $0.007 * *$ \\
\hline Total protein $(\mathrm{g} / \mathrm{dL})$ & $7.2 \pm 0.09$ & $7.1 \pm 0.08$ & 0.395 & $7.1 \pm 0.08$ & $7.3 \pm 0.12$ & 0.055 \\
\hline Albumin $(g / d L)$ & $4.4 \pm 0.06$ & $4.3 \pm 0.07$ & 0.333 & $4.3 \pm 0.05$ & $4.4 \pm 0.08$ & 0.053 \\
\hline Total bilirubin $(\mathrm{mg} / \mathrm{dL})$ & $0.68 \pm 0.03$ & $0.72 \pm 0.05$ & 0.402 & $0.7 I \pm 0.04$ & $0.65 \pm 0.04$ & 0.213 \\
\hline AST (U/L) & $28.9 \pm 2.5 \mathrm{I}$ & $28.5 \pm 3.06$ & 0.617 & $30.4 \pm 4.49$ & $32.4 \pm 6.15$ & 0.486 \\
\hline $\mathrm{ALT}(\mathrm{U} / \mathrm{L})$ & $25.1 \pm 3.90$ & $24.6 \pm 4.14$ & 0.445 & $25.6 \pm 4.76$ & $26.2 \pm 5.26$ & 0.434 \\
\hline ALP (U/L) & $239.8 \pm 14.5$ & $248.5 \pm 19.5$ & 0.842 & $245.3 \pm 17.8$ & $244.5 \pm 14.2$ & 0.754 \\
\hline $\mathrm{LDH}(\mathrm{U} / \mathrm{L})$ & $212.8 \pm 8.4$ & $205.5 \pm 6.6$ & 0.129 & $205.8 \pm 8.1$ & $206.8 \pm 7.9$ & 0.947 \\
\hline$\gamma$-GTP $(\mathrm{U} / \mathrm{L})$ & $31.1 \pm 5.28$ & $32.3 \pm 5.25$ & 0.578 & $32.0 \pm 5.70$ & $34.4 \pm 6.36$ & 0.953 \\
\hline Cholinesterase (U/L) & $348.6 \pm 16.9$ & $341.2 \pm 16.4$ & $0.028^{*}$ & $340.1 \pm 17.5$ & $355.2 \pm 20.2$ & $0.022^{*}$ \\
\hline Creatine kinase (U/L) & $138.8 \pm 2 \mid .3$ & $119.9 \pm 14.1$ & 0.358 & $127.4 \pm 17.9$ & $125.5 \pm 16.5$ & 0.509 \\
\hline Blood urea nitrogen (mg/dL) & $|5.6 \pm 0.9|$ & $16.0 \pm 1.05$ & 0.895 & $15.3 \pm 0.88$ & $15.2 \pm 0.77$ & 0.965 \\
\hline Creatinine (mg/dL) & $0.7 I \pm 0.05$ & $0.73 \pm 0.06$ & 0.225 & $0.7 I \pm 0.05$ & $0.70 \pm 0.04$ & 0.521 \\
\hline Total cholesterol (mg/dL) & $204.6 \pm 7.5$ & $200.1 \pm 6.3$ & 0.161 & $198.6 \pm 5.2$ & $197.3 \pm 6.9$ & 0.598 \\
\hline HDL cholesterol (mg/dL) & $58.8 \pm 2.50$ & $56.6 \pm 2.65$ & 0.333 & $58.1 \pm 2.60$ & $60.5 \pm 2.69$ & 0.336 \\
\hline LDL cholesterol (mg/dL) & $117.9 \pm 6.1$ & $113.7 \pm 5.9$ & 0.088 & $1 \mid 4.5 \pm 5.4$ & $\mid 12.1 \pm 5.9$ & 0.559 \\
\hline Triglyceride (mg/dL) & $148.4 \pm 16.6$ & $181.9 \pm 33.6$ & 0.493 & $153.9 \pm 27.0$ & $138.0 \pm 15.8$ & 0.582 \\
\hline Blood sugar (mg/dL) & $109.6 \pm 11.0$ & $112.2 \pm 9.2$ & 0.982 & $116.9 \pm 12.6$ & $105.6 \pm 7.8$ & 0.768 \\
\hline Hemoglobin $A_{l c}(\%)$ & $5.6 \pm 0.18$ & $5.6 \pm 0.20$ & $0.039 *$ & $5.6 \pm 0.21$ & $5.6 \pm 0.20$ & 0.366 \\
\hline D-dimer $(\mu \mathrm{g} / \mathrm{mL})$ & $0.58 \pm 0.04$ & $0.61 \pm 0.05$ & 0.348 & $0.55 \pm 0.02$ & $0.57 \pm 0.04$ & 0.668 \\
\hline
\end{tabular}

Notes: Values are represented as mean \pm standard error. Statistical significance, $* \mathrm{P}<0.05$; $* * P<0.0$ I.

Abbreviations: AST, aspartate aminotransferase; ALT, alanine aminotransferase; ALP, alkaline phosphatase; LDH, lactate dehydrogenase; $\gamma$-GTP, gamma-glutamyl transpeptidase.

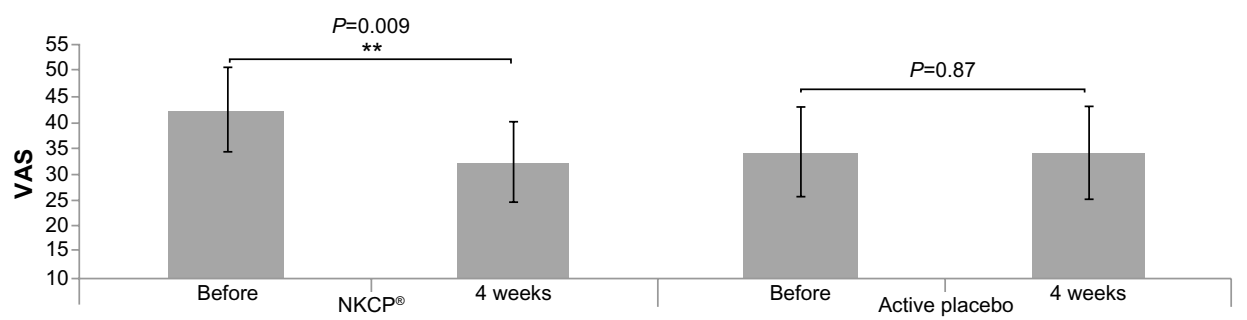

Figure I Changes in VAS score for shoulder stiffness after 4 weeks compared with baseline in patients taking NKCP ${ }^{\circledR}$ (Daiwa pharmaceutical Co., Ltd.) or active placebo. Notes: The vertical bar indicates the standard error. Statistical significance, $* * P<0.01$.

Abbreviation: VAS, visual analog scale.

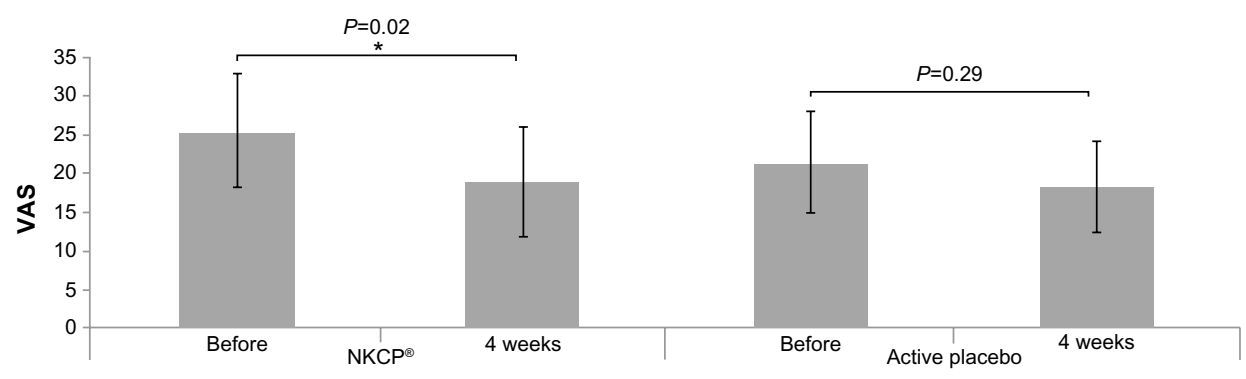

Figure 2 Changes in VAS score for low back pain after 4 weeks compared with baseline in patients taking NKCP ${ }^{\circledR}$ (Daiwa pharmaceutical Co., Ltd.) or active placebo. Notes: The vertical bar indicates the standard error. Statistical significance, $* P<0.05$.

Abbreviation: VAS, visual analog scale. 


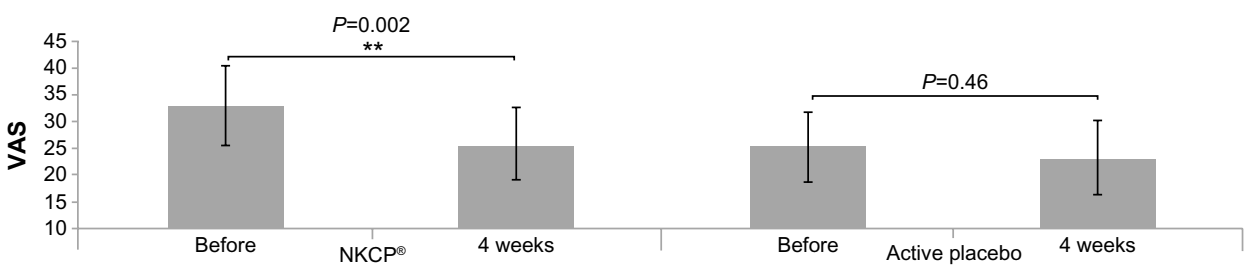

Figure 3 Changes in VAS score for coldness of the extremities after 4 weeks compared with baseline in patients taking NKCP ${ }^{\circledR}$ (Daiwa pharmaceutical Co., Ltd.) or active placebo. Notes: The vertical bar indicates the standard error. Statistical significance, $* * P<0.01$. Abbreviation: VAS, visual analog scale.

with increasing severity of the disease. ${ }^{10}$ In the present study, although the routine blood examination results revealed no marked abnormalities, many patients complained of low back pain, headache, shoulder stiffness, and coldness of the extremities, all of which may be partly explained by blood flow disturbances. Low back pain is an epidemiological problem that is common in the general population, and low back pain is the most dominant reason for frequent visits to general practitioners. ${ }^{11}$ Although the cause of low back pain is not fully understood, atherothrombotic disease of the feeding arteries of the lumbar spine has been considered to be a possible underlying factor; additionally, a diminished blood supply is reportedly closely related to low back pain. ${ }^{12,13}$ In this study, improvements in the blood supply by $\mathrm{NKCP}^{\circledR}$ accordingly led to the relief of low back pain. Furthermore, the results of this study suggest that other symptoms of blood flow disturbances, such as shoulder stiffness and coldness of the extremities, also improved by the intake of $\mathrm{NKCP}^{\circledR}$. Although statistical significances were observed in changes of these symptoms, as sample size was too small, further researches may confirm these results.

Regarding the results of blood tests, some blood chemistry parameters had abnormal values because subjects were patients of lifestyle diseases in the present study. However, the patients were well-controlled with medical intervention and had no advanced thrombotic or vascular diseases. Although a 4-week course of $\mathrm{NKCP}^{\circledR}$ significantly increased the cholinesterase and $\mathrm{HbA}_{1 \mathrm{c}}$ levels, and a 4-week course of active control significantly increased the platelet count and cholinesterase level, all of these parameters were within the reference ranges, and changes were small. Therefore, we believe that these differences did not affect the results.

Various medications are used to reduce the abovedescribed symptoms. However, because of limitations and concerns such as availability, cost, and adverse effects of medications, a proportion of the population, especially in Asia, has turned to complementary and alternative medicine. ${ }^{14,15}$ Japan authorities have recommended a diet balanced with staple foods, mainly Japanese foods, to maintain and improve patients' health status and to prevent chronic noncommunicable diseases. ${ }^{16}$ Therefore, functional food which prevents the development of such chronic diseases has become attractive to many people. $\mathrm{NKCP}^{\circledR}$, which is derived from Japanese traditional food, is one of the functional foods. Direct fibrinolytic and serine protease activity for human blood and antithrombotic activity in rats after administrating orally were confirmed for $\mathrm{NKCP}^{\circledR}{ }^{5,6}$ Furthermore, blood pressure-lowering effects for the patients have been found previously ${ }^{7}$ and also were shown in the present result. Therefore, $\mathrm{NKCP}^{\circledR}$ has been considered to contribute to the prevention of vascular events in patients with lifestyle diseases. In this study, we suggested that Japanese functional food improved subjective symptoms, owing to the disturbance of blood flow. As functional food is derived from Japanese

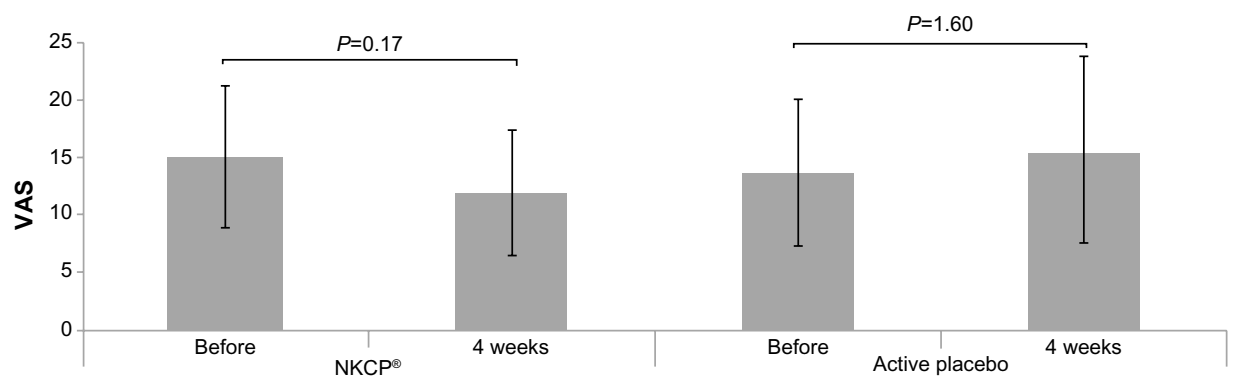

Figure 4 Changes in VAS score for headache after 4 weeks compared with baseline in patients taking NKCP ${ }^{\circledR}$ (Daiwa pharmaceutical Co., Ltd.) or active placebo. Note: The vertical bar indicates the standard error.

Abbreviation: VAS, visual analog scale. 
traditional food, natto, and does not contains other chemical substances, it is considered as safe. Thus, $\mathrm{NKCP}^{\circledR}$ may be useful for patients instead of using medications.

The most important limitation of this study is that sample size is small with a short observation period. However, as this study was performed as a cross-over, double-blind trial, there is some scientific reliability. Another limitation is that the participants of the present study were all women. The outcome of the recruitment process for participants coincidentally yielded an all-woman subject pool of participants. Further research may clarify the whether similar results can be obtained for male patients.

\section{Conclusion}

For patients with lifestyle diseases, taking $\mathrm{NKCP}^{\circledR}$ improved the blood flow and subsequently relieved low back pain, shoulder stiffness, and coldness of the extremities, all of which were caused by blood flow disturbances. The use of dietary supplements derived from the Japanese traditional food natto provides additional effects of relieving subjective symptoms for patients with lifestyle diseases who are receiving medical care. Further researches with a large enough sample size may confirm the present results.

\section{Disclosure}

This study was financially supported by Daiwa Pharmaceutical Co, Ltd. MH received a lecture fee from Daiwa Pharmaceutical Co, Ltd. KH and KM report no conflicts of interest in relation to this work. The authors report no other conflicts of interest in this work.

\section{References}

1. Artaud-Wild SM, Connor SL, Sexton G, Connor WE. Differences in coronary mortality can be explained by differences in cholesterol and saturated fat intakes in 40 countries but not in France and Finland. A paradox. Circulation.1993;88(6):2771-2779.
2. Menotti A, Keys A, Blackburn H, et al. Comparison of multivariate predictive power of major risk factors for coronary heart diseases in different countries: results from eight nations of the Seven Countries Study, 25-year follow-up. J Cardiovasc Risk. 1996;3(1):69-75.

3. UNESCO [webpage on the Internet]. Lists of intangible cultural heritage and Register of best safeguarding practices. Available from: http:// www0.nih.go.jp/eiken/english/research/pdf/dris2005_eng.pdf\#search= 'Dietry+Reference+Intakes+for+Japanese+\%282005\%29'. Accessed January 8, 2015.

4. Sumi H, Hamada H, Tsushima K, Mihara H, Muraki H. A novel fibrinolytic enzyme (nattokinase) in the vegetable cheese natto: a typical and popular soybean food Japanese diet. Experimentia. 1987;43(10): 1110-1111.

5. Fujita M, Nomura K, Hong K, Ito Y, Asada A, Nishimuro S. Purification and characterization of a strong fibrinolytic enzyme (nattokinase) in the vegetable cheese natto, a popular soybean fermented food in Japan. Biochem Biophys Res Commun. 1993;197(3):1340-1343.

6. Omura K, Hitosugi M, Zhu X, Ikeda M, Maeda H, Tokudome S. A newly derived protein from Bacillus subtilis natto with both antithrombotic and fibrinolytic effects. J Pharmacol Sci. 2005;99(3):247-251.

7. Hitosugi M, Ikeda M, Zhu X, et al. Anticoagulant and fibrinolytic effects of functional food materials produced by Bacillus subtilis natto. J Japan Soc Biorheol. 2007;21(1):35-40.

8. Hitosugi M, Hamada K, Misaka K, Ichihashi K. Effects of Bacillus natto products on blood pressure in patients with lifestyle diseases. J Hypertens. 2014;3:135.

9. Bulur S, Ozhan H, Erden I, et al. Efficacy of olmesartan therapy on fibrinolytic capacity in patients with hypertension. Blood Coagul Fibrinolysis. 2011;22(1):29-33.

10. Yamada K, Sato-Mito N, Nagata J. Health claim evidence requirements in Japan. J Nutr. 2008;138(6):1192S-1198S.

11. Hart LG, Deyo RA, Cherkin DC. Physician office visits for low back pain. Frequency, clinical evaluation, and treatment patterns from a US national survey. Spine (Phila Pa 1976). 1995;20(1):11-19.

12. Kauppila LI. Atherosclerosis and disc degeneration/low-back pain - a systematic review. Eur J Vasc Endovasc Surg. 2009;37(6):661-670.

13. Deyo RA, Weinstein JN. Low back pain. $N$ Engl J Med. 2001;344(5): 363-370.

14. Chen KJ, Hui KK, Lee MS, Xu H. The potential benefit of complementary/alternative medicine in cardiovascular diseases. Evid Based Complement Alternat Med. 2012;2012:125029.

15. Wang J, Xiong X. Evidence-based Chinese medicine for hypertension. Evid Based Complement Alternat Med. 2013;2013:978398.

16. Ministry of Health, Labor and Welfare. [Dietary Reference Intakes for Japanese]. Tokyo: Office of Lifestyle-Related Disease Control, Ministry of Health, Labor and Welfare; 2005. http:/wwwo.nih.go.jp/ eiken/english/research/pdf/dris2005_eng.pdf\#search='Dietry+Refere nce+Intakes+for+Japanese+\%282005\%29
International Journal of General Medicine

\section{Publish your work in this journal}

The International Journal of General Medicine is an international, peer-reviewed open-access journal that focuses on general and internal medicine, pathogenesis, epidemiology, diagnosis, monitoring and treatment protocols. The journal is characterized by the rapid reporting of reviews, original research and clinical studies across all disease areas.

\section{Dovepress}

A key focus is the elucidation of disease processes and management protocols resulting in improved outcomes for the patient. The manuscript management system is completely online and includes a very quick and fair peer-review system. Visit http://www.dovepress.com/ testimonials.php to read real quotes from published authors. 